\title{
Assessment and Management of Cardiorespiratory Deconditioning with Beninese Visually Impaired Subjects
}

\author{
Salifou Kora Zaki Yarou ${ }^{1 *}$, Mouhamed Mansourou Lawani ${ }^{1}$, Lafiou Yessoufou ${ }^{1}$, Toussaint \\ Kpadonou $^{2}$ and Ismaël Barres ${ }^{1}$
}

${ }^{1}$ Laboratory of Biomechanics and Performance (LaBioP) INJEPS-UAC, France

${ }^{2}$ Department of Rehabilitation and Fonctionnal Readjustment, France

*Corresponding author: Salifou Kora Zaki Yarou, Laboratory of Biomechanics and Performance (LaBioP) INJEPS-UAC - Department

of Rehabilitation and Fonctionnal Readjustment CNHU-HKM, Novo (BENIN), France

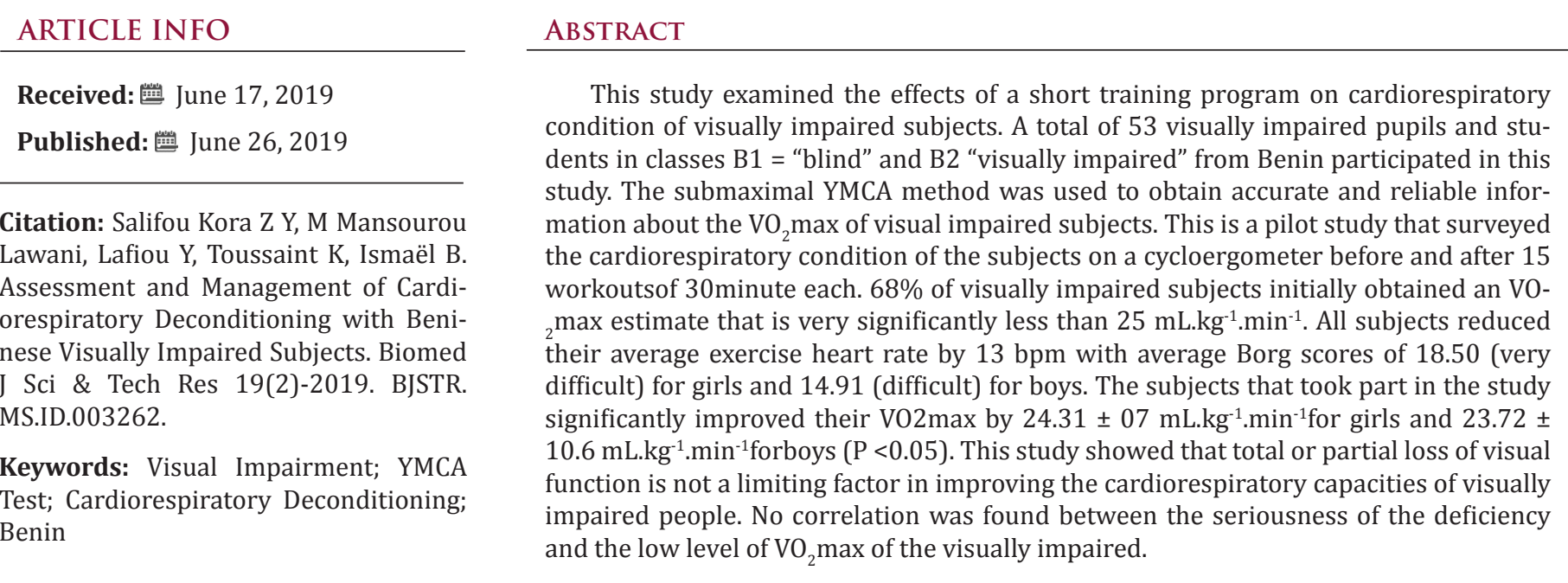

\section{Introduction}

In many African countries in general, especially in Benin, being handicaped results in an image of irreducible disability. Despite the legal arsenal in their favor, these people experience situations of exclusion from the practice of Sport and Physical Education [1] due to a deficiency. Thus, they are generally constrained to decubitus and immobility with cardiorespiratory and musculoskeletal complications. According to WHO in 2010, physical inactivity is the $4^{\text {th }}$ risk factor for overall mortality. Visually impaired people are consistently referred to as those with very low physical activity, unlike other normal children. Prolonged decubitus sometimes leads to exercise mismatch with changes in skeletal muscle that may aggravate a pre-existing heart failure, a bronchial congestion, and even low respiratory infections [2,3]. De Potter (2006) reports that the physical condition of the visually impaired person is less than normal and correlated with the seriousness of the impairment. Despite these known complications, no study in Benin has investigated on the methods of caring for this category of people. Visually impaired people account for $37.4 \%$ (4.8\% of blind people and $32.5 \%$ of visually impaired people) in the total population of persons with disabilities, estimated at 102997 according to the third general population and habitat census of February 2002. However, they are aware of their ability to practice several sport activities with technical and human assistance. Unfortunately, the level of care for this category of people is low or non-existent in adapted physical activity programs.

Therefore, the particular interest of this study is based on subjects with visual impairment, thus a disability that can limit their autonomy, their ability to develop motor skills and functional abilities. The study attempts to answer the lack of a simple method allowing the visually impaired (VI) to autonomously improve his cardiorespiratory condition on the cycloergometer. 


\section{Materials and Methods}

\section{Participants}

The study population is represented by all blind (B1) and visually impaired (B1) pupils, students and craftsmen aged between 15 and 39 years. They mainly come from four of the six Centers for the Social Promotion of the Blind and Amblyopic People of Benin (CPSAA in Natitingou and Parakou in the northern part of Benin, CPSAA in Djanglanmè and the one of Ségbèya in Cotonou in the southern part). $58 \mathrm{VI}$ subjects with an average age of 23.06 \pm 15.26 years for girls and $23.84 \pm 6.10$ years for boys took part of this study. To participate in the study, the inclusion criteria were: bea visually impaired person of at least fifteen years old from one of the Benin CPSAAs; not to have a critical heart disease and agree to be committed at the CPSAA of Sègbèya in Cotonou during the entire period of data collection. The criteria for non-inclusion in the study were: an intellectual disability that could have been associated with blindness; A pathology against the practice of Physical Activities.

It was excluded from the study those subjects whose irregularity during the workouts was observed for more than three sessions or declared ill. On this basis, five VI subjects were excluded from the study and 53 participated in the study.

\section{Experimental Protocol}

The experimental protocol consisted first of all of researching and obtaining from the ministry in charge of handicapped persons two practical training contracts of three months in the CPSAAs of Benin (Contract $\mathrm{N}^{\circ} 054 / \mathrm{MFSN} / \mathrm{DC} / \mathrm{SGM} / \mathrm{DRH} / \mathrm{SAof}$ November 04, 2010 renewed by the contract $\mathrm{N}^{\circ} 007 /$ MFASSNHPTA/DC/SGM/ DRH/SA of February 21, 2012). The aim of this first approach was to evaluate the possibilities of integrating VIs into the practice of Sport and Physical Education in the host schools and, on the other hand, the pedaling capacity of VIs on a tandem bicycle (the only one in good condition in Benin) or on an ergocycle. With the help of the directors of these centers, a focus group helped to have information about age, the degree of vison loss. In addition to the school records, an ophthalmologist examined all the subjects present at the site of regrouping (CPSAA de Sègbèya) to confirm the class of the VI. The ability of VI to practice fitness activities was reported thanks to the Physical Activity Readiness Questionnaire (PAR-Q) in accordance with the Canadian Society for Exercise Physiology guidelines (2010).

Later, with telephone contacts and the help of a teacher and a sports instructor from the Sègbèya CPSAA, 58 VIs were regrouped and housed in the center. The importance of the study was further explained to them, their health benefits, the biometric measurements to be taken, and the experimental protocol. The informed consent sheet was read to them and those who agreed have signed on the back of it. A total of 53 VIs voluntarily agreed to participate in the study, which was approved by the Research Ethics Committee of the Institute of Applied Biomedical Sciences (CER-ISBA) of Benin by decision $\mathrm{N}^{\circ} 18$ on $27 / 03 / 2013$. The YMCA test is based on the difficulty of inserting the VI into the practical courses of Physical Education, the failure of the tandem bicycles and the ability of the VIs on a cycloergometer observed during the workouts at the CPSAA and at SRRF of CNHU.

The experimentation is characterized by two phases: - A first phase before the test where the height and body mass were taken respectively using a measuring scale and an electronic scale (brand: SECA, JJA: 157 AV Charles Floquet 93150 (France). The heart rate at rest and exercise measured before and during the test, using heart rate monitors (type: RS 100; brand: Polar Electro Oy Professorintie 5 FIN-90440 (Finland).

A second test phase on three ergocycles (Polym Gymna ErgoFit 450; Brand: Polar), all equipped with an electronic meter that indicates the heart rate at exercise, the distance traveled, the duration and speed of pedaling (45 to 50rpm). Only the average values of the heart rateduring the exercisementioned on the screen of the microprocessor watch during the last 15 seconds of each stage of 3 minutes were retained. Between the first (T1) and third (T3) assesment, an inter-cycle assessment(T2) was carried out after 7 workouts to ensure that parameters changed, and adjustments were made to the initial workload. The Borg rating of perceived exertion scale was used for the subjective assessment of the intensity of the effort by the subjects who are asked at the end of each session of $3 \mathrm{~min}$, some questions about how they feel the effort, in order to avoid certain risky situations. The experiments were performed at SRRF between 1:00 pm and 2:30 pm in a temperaturecontrolled room with a fan, in the presence of two physiotherapists. The measurements were taken before (at the end of the practical workouts) and after the workouts on cycloergometers. Estimates of maximum oxygen consumption $\left(\mathrm{VO}_{2} \mathrm{max}\right)$ were made using the equations of the multi-level model to calculate the slope of the V02max curve according to the evolution of the heart rate at the last two powers in accordance with YMCA method: $\mathrm{VO}_{2} \max =\mathrm{SM}_{2}$ $+[\mathrm{b} .(\mathrm{HR}$ max $-\mathrm{HR} 2)]$ with $\mathrm{SM}_{2}$, the oxygen cost at the last stage; (b) the slope of the curve; theoretical HR max $=220$ - age and HR2 the average heart rate at the last stage [4]. Subjects were given a light meal during recess time between 10:00 am and 10:30 am prior to their departure by bus at 12:30 pm to the site of the experiment Table 1.

Table 1: Heart rate and charge levels for the different levels of the YMCA test on an ergometric bicycles.

\begin{tabular}{|c|c|c|c|c|}
\hline \multicolumn{5}{|c|}{$150 \mathrm{kpm} \cdot \mathbf{m i n}-1$ (0.5 kp or 25 W) } \\
\hline \multicolumn{5}{|c|}{ HR during the last minute of the last stage } \\
\hline $\begin{array}{c}\text { Subsequent } \\
\text { Stages }\end{array}$ & $<80 \mathrm{bpm}$ & $80-89 \mathrm{bpm}$ & $90-100 \mathrm{bpm}$ & $>100 \mathrm{bpm}$ \\
\hline $2^{\text {nd }}$ & $125 \mathrm{~W}$ & $100 \mathrm{~W}$ & $75 \mathrm{~W}$ & $50 \mathrm{~W}$ \\
\hline $3^{\text {rd }}$ & $150 \mathrm{~W}$ & $125 \mathrm{~W}$ & $100 \mathrm{~W}$ & $75 \mathrm{~W}$ \\
\hline $4^{\text {rd }}$ & $75 \mathrm{~W}$ & $150 \mathrm{~W}$ & $125 \mathrm{~W}$ & $100 \mathrm{~W}$ \\
\hline
\end{tabular}

\section{Workouts}

The experiment began 2 months after the $2^{\text {nd }}$ practical training course of VIs. During these internship periods, the VIs participated, with the help of classmates, in Physical Education and general fitness classes. The 15 workouts(endurance) for visually impaired 
subjects took place in the afternoons at the SRRF exercise room averaging 3 times per week. They included static heating of 5 minutes, 15 to 20 minutes of cycloergometer, 5 minutes of guided walking in the aisles of SRRF (active recovery) and 30 to 45 minutes of isostretching exercises. Each session lasted about 1 hour and 30 minutes (including the time of weight gain and the heart rate at rest before the start of the session). The subjects were trained with an intensity that varied between 70 and $85 \%$ of the theoretical maximum HR (135-160 beats per minute) under the supervision of a physiotherapist. The pedaling speed varied from 45 to 50 rotations per minute and the power shifted from 15 watt initially to 125 watt at the final stage following theBorg rating of perceived exertion scale. Isostretching exercises were chosen to strengthen the respiratory muscles and the overall flexibility of VI subjects. Each exercise was practiced three times for 10 seconds (the first time to understand (using bio-feedbacks) the second in order to correct ourselves, the third time for the correct performance by the visual impaired person). A goalball session was organized every weekend at the CPSAA for the benefit of the participants.

\section{Measures}

Anthropometric Measures: The size was measured barefoot at the first session for all VI subjects, dressed in shorts and a lightweight T-shirt, using a gauge that was unrolled until it rests on the head of the subject. Body mass was measured under the same conditions using the person scale.

Cardiorespiratory Capacity: The heart rate at exercise was taken on the screen of each microprocessor watch for the last 15 seconds of each minute. The aerobic capacity was evaluated indirectly using the YMCA test on a cycloergometer according to Golding (2000) and the recommendations of the Canadian Society for Exercise Physiology (2010). The YMCA test is based on 2 to 5 consecutive 3-minute efforts on a cycloergometer with powers individually assigned according to the heart rate evolution in the last 15 seconds of the current stage. The test was preceded by 5 minutes warm-up exercise's. The slope (b) of the equation was calculated from the above and below maximum oxygen costs and from the average values of HR at the last two powers carried out. It was used to calculate the VO2max of the formula: $\mathrm{VO}_{2} \max =\mathrm{SM}_{2}+$ b(HRmax - $\left.\mathrm{HR}_{2}\right)$.

Statistical Analysis: The data collected from the participants was entered with the software Epi Data 3.1 after the input mask and the input control program were created. Observations and input errors were minimized by the file clearance. The file obtained after clearance was transferred to the software SPSS version 17.0 and then the tables are released according to the analysis plan. The formatting of the results (tables and graphs) was done with Excel and Word. The different results are expressed by their average and standard deviation in tables. The results that are obtained before and after the workouts were compared to better assess the effects of the training program. We performed cross-analyzes using KHI2 and Cramer's V to better express the evolution of the different parameters according to the seriousness of the impairment, the sex and the age group. Then, the different measurements made before and after (T1 and T3) were compared by an analysis of variance (Anova) on repeated measurements in order to identify the significant differences. Statistical significance was set at $\mathrm{p}<0.05$.

\section{Results}

At the begining, a significant difference was observed according to the degree of vision loss ( $p=0.003)$, $\operatorname{sex}(p=0.029)$ for significantly different workloads ( $p=0.05$ ) as far as the resistance to the effort is concerned. (Table 2 and Figure 1). No significant differences were noticed at the end of the workouts. The heterogeneity of the study population was noted at the level of VI boys through two $\mathrm{VO}_{2}$ max peaks observed at 41.67 et 43.19 mL.kg-1.min-1. However, no significant difference was found between VI girls and boys during the first test with the variable $\mathrm{VO}_{2}$ max that is relatively very low for all the studied subjects (Figure 2). An insignificant effect related to the degree of vision loss and sex was noted at T1 for the aerobic capacity. Table 3 shows the low average level of $\mathrm{VO}_{2}$ max of $\mathrm{VI}$ subjects and the very significant improvements in $\mathrm{VO}_{2}$ max obtained especially with the B1 subjects of the 20-24 age group (48.50 \pm 8.01 $\mathrm{mL} \cdot \mathrm{kg}^{-1} \cdot \mathrm{min}^{-1}$ ) as well as with visually impaired girls of the same age group $\left(46,28 \pm 0,70 \mathrm{~mL} \cdot \mathrm{kg}^{-1} \cdot \mathrm{min}^{-1}\right)$ as a result of the training program.

Table 2: Resistance to effort of visually impaired subjects during the YMCA test.

\begin{tabular}{|c|c|c|c|c|c|c|}
\hline \multicolumn{7}{|c|}{ Successful Completion of The YMG7:M27CA Test } \\
\hline \multirow{2}{*}{ Variables } & \multicolumn{3}{|c|}{$\mathrm{T} 1$} & \multicolumn{3}{|c|}{ T3 } \\
\hline & Yes & No & $\mathrm{p}$ value & Yes & No & $\mathrm{p}$ value \\
\hline \multicolumn{7}{|c|}{ *Seriousness of the disability } \\
\hline Blind & 7 & 31 & \multirow{2}{*}{0.003} & 31 & 7 & \multirow{2}{*}{0.282} \\
\hline Visually impaired & 9 & 6 & & 14 & 1 & \\
\hline \multicolumn{7}{|c|}{ *Sex } \\
\hline Female & 1 & 13 & \multirow{2}{*}{0.029} & 11 & 3 & \multirow{2}{*}{0.44} \\
\hline Male & 15 & 24 & & 34 & 5 & \\
\hline \multicolumn{7}{|c|}{ *Age } \\
\hline Teenager (15-19 years old) & 4 & 6 & \multirow{3}{*}{0.755} & 10 & 0 & \multirow{3}{*}{0.32} \\
\hline Young (20-24 years old) & 7 & 18 & & 20 & 5 & \\
\hline Adult (25-39 years old) & 5 & 13 & & 15 & 3 & \\
\hline
\end{tabular}




\begin{tabular}{|c|c|c|c|c|c|c|}
\hline \multicolumn{7}{|c|}{ * Workload (in watt) } \\
\hline & Girls & Boys & & Girls & Boys & \\
\hline 20 & 1 & 0 & & 0 & 0 & \\
\hline 25 & 2 & 3 & & 0 & 0 & \\
\hline 50 & 6 & 7 & 0.05 & 2 & 3 & 0.12 \\
\hline 75 & 4 & 21 & & 10 & 19 & \\
\hline 100 & 0 & 1 & & 2 & 12 & \\
\hline \multicolumn{7}{|c|}{ * RPE scale } \\
\hline 15 & 0 & 3 & & 4 & 19 & \\
\hline 17 & 3 & 12 & 0.39 & 7 & 14 & 0.25 \\
\hline 19 & 6 & 18 & & 2 & 1 & \\
\hline 20 & 4 & 5 & & 0 & 0 & \\
\hline
\end{tabular}

Table 3: Comparison of $\mathrm{VO}_{2}$ max estimates according to sex, age group and the degree of the impairment during the $1^{\text {st }}$ and $3^{\text {rd }}$ test.

\begin{tabular}{|c|c|c|c|c|}
\hline & $\begin{array}{c}\text { 15-19 Years Old } \\
\text { T1 - T3 }\end{array}$ & $\begin{array}{c}\text { 20-24 Years Old } \\
\text { T1 - T3 }\end{array}$ & $\begin{array}{l}\text { 25-39 Years Old } \\
\text { T1 - T3 }\end{array}$ & $\begin{array}{l}\text { P Value } \\
\text { T1 - T3 }\end{array}$ \\
\hline \multicolumn{5}{|c|}{${ }^{*}$ Estimates of $\mathrm{VO}_{2} \max _{\mathrm{x}}\left(\mathrm{mL} \cdot \mathrm{kg}^{-1} \cdot \mathrm{min}^{-1}\right)$} \\
\hline \multicolumn{5}{|c|}{ Average } \\
\hline Boys B1 & $16.84-42.42$ & $28.54-48.50$ & $20.55-47.39$ & $0.003-0.28$ \\
\hline Boys B2 & $29.32-51.82$ & $22.79-44.94$ & - & \\
\hline Girls B1 & - & $12.15-36.99$ & - & $002-044$ \\
\hline Girls B2 & - & $18.72-46.28$ & - & $0.02-0.97$ \\
\hline \multicolumn{5}{|c|}{ Standard deviation } \\
\hline Boys B1 & $2.77-7.84$ & $10.08-8.01$ & $9.32-6.95$ & \\
\hline Boys B2 & $8.31-7.31$ & $12.78-14.04$ & - & \\
\hline Girls B1 & - & $6.88-8.95$ & - & \\
\hline Girls B2 & - & $9.63-0.70$ & - & \\
\hline \multicolumn{4}{|c|}{ Median value } & \\
\hline Boys B1 & $16.27-40.54$ & $25.39-48.50$ & $15.57-47.06$ & \\
\hline Boys B2 & $31.00-50.11$ & $18 ., 63-44.94$ & - & \\
\hline Girls B1 & & $10.12-35.94$ & - & \\
\hline Girls B2 & 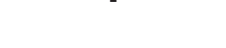 & $14.94-45.77$ & - & \\
\hline
\end{tabular}

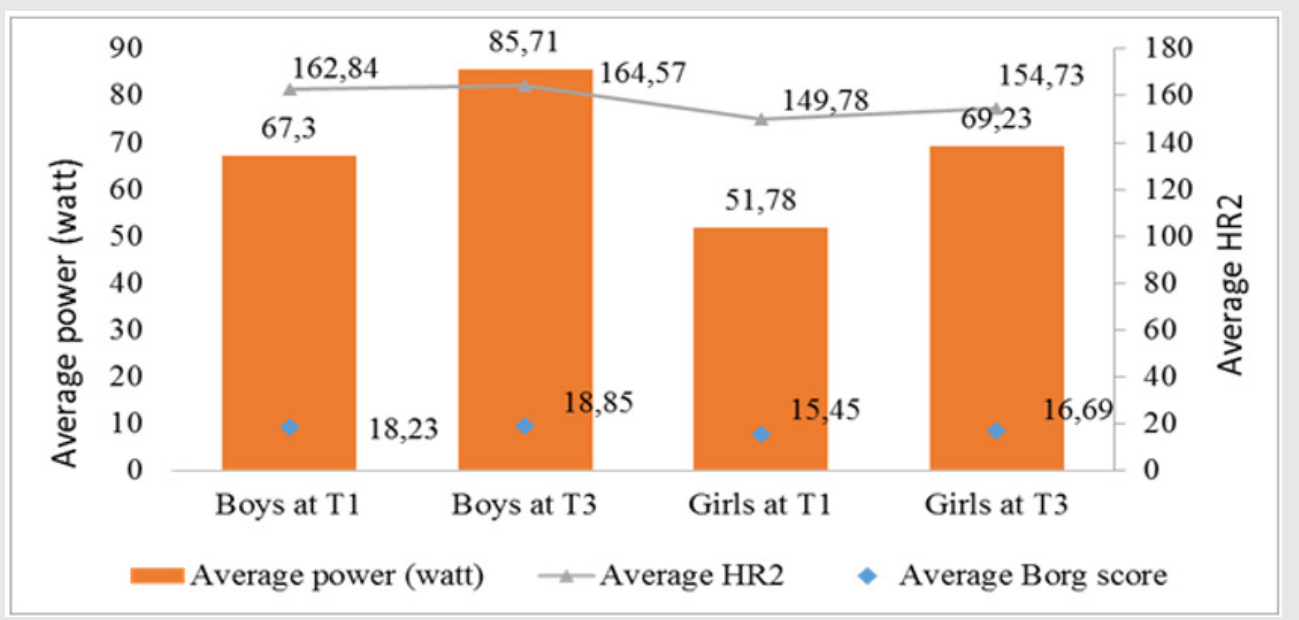

Figure 1: Evolution of the heart rate according to the workload at the final stage. Figure 1 shows a significant reduction of the average heart rate for higher workloads that is difficult for all the participants to put up with at the end of the training program. 


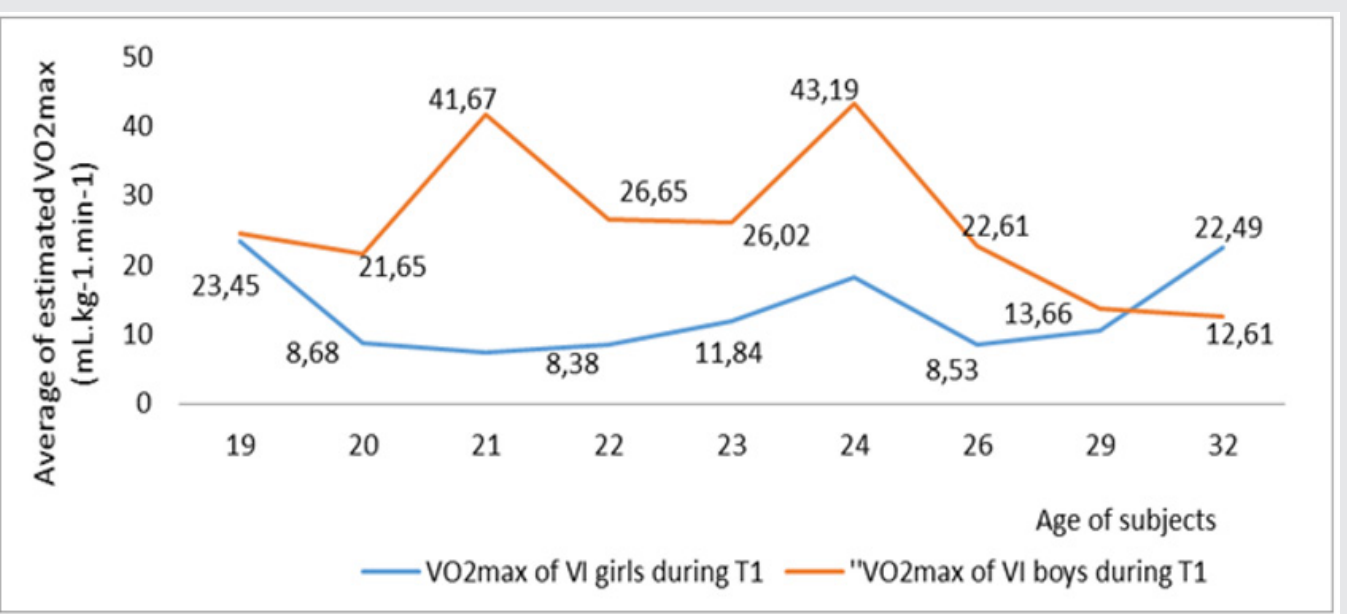

Figure 2: Evolution of the maximum oxygen consumption according to the age and the sex of the subject.

Figure 2 shows that there is no significant difference between VI girls and boys during the first test with the variable $\mathrm{VO}_{2} \mathrm{max}$ that is relatively very low for all the studied subjects.

\section{Discussion}

The analysis of the quantitative and qualitative data collected during the initial (T1) and final (T3) test of the training program allowed to explain and justify that the total or partial loss of the visual function does not represent a hindrance or an obstacle to the improvement of certain basic parameters of the physical condition such as aerobic capacity. It also shows that the "blind" B1 reacts in a similar way to training as his visually impaired peer B2 who very often uses his "remaining sight".

\section{Identification and Participants' Level of Practice of Adapted Physical Activities}

This study helped to show for the first time the physiological effect of a short workout of the visually impaired subjects on cycloergometer. The subjects that took part of the study were $86 \%$ of those exempted from doing fitness and who had an increased physical inactivity before starting the study. Its main contribution is to provide baseline values on the physical and aerobic capacity of people living with a visual impairment. The only recent study found in the literature was about training in tandem cycling during which the visually impaired subject does not have fully pedaling autonomy. The workout on the cycloergometer thus reinforces the research in the field of APA by offering a complete pedaling autonomy to the visually impaired subjects. One of the most important results is to have confirmed the view that visual impairment is not a limiting factor of the workouts effects on the development of cardiorespiratory endurance physical parameters for the visually impaired subjects [5].

The sex ratio $\mathrm{F} / \mathrm{H}$ of 0.35 , shows the low enthusiasm of the girls to the practice of physical activities in the Beninese society in general. Given the average age of the subjects $(23,44 \pm 5.67$ years $)$ and the level of schooling of the subjects, we can expect a good response both cognitively and in terms of motor intelligence [6] of all subjects during the assessment test and workouts.

\section{Assessment of The Cardiorespiratory Capacity of Visually Impaired Subjects}

The YMCA test on cycloergometer allowed to evaluate the functional capacity to the effort and the physical qualities of the visually impaired subjects. Less physical demand for $70 \%$ of participants during the first YMCA test on cycloergometer was observed. The massive failure of this test is noted as a result of the participants' inability to maintain the pedaling rate or to stop pedaling. They feel the effort extremely difficult with the RPE scale, what was particularly evident with the visually impaired boys and girls. On the other hand, $30 \%$ (2\% of girls and $28 \%$ of boys) of participants finished the three stages with an average Borg score of 18.23 (last stage) "very difficult" for boys and 18.85 "extremely difficult" for girls (Figure 1). The average power of 67.3 watt for boys and 51.78 watt for girls at the final stage of the first test increased the average HR2 at $162.84 \mathrm{bpm}$ and $164.57 \mathrm{bpm}$ Figure 1.

Thus, at the $5 \%$ threshold, the success rate was significantly associated with the degree of the impairment, sex and age of the target being studied. In addition, the two groups, according to the degree of the impairment, differed significantly from each other during the first test. However, boys showed better resistance compared to girls. The Borg scale averages are not significantly different at the $5 \%$ threshold during the first test. These figures should be considered with caution because at the last stage of the test, most subjects only fit within the first minute of this stage. The only heart rate recorded in the last 15 seconds in the first minute of the last stage is taken directly as the average $\mathrm{HR}_{2}$ of the subject at this level. Previous studies have shown that the physical fitness of the visually impaired is limited. Lieberman et [7] note that these studies used a variety of methods, including cardiovascular endurance, muscle strength, endurance, and physical composition. The degree of vision loss was significantly different, making it difficult and problematic to compare the results. But the appreciation of these results from the first YMCA test in relation to aerobic capacity seems to be more interesting. 
Indeed, cardiorespiratory endurance, considered to be the best index of functional capacity $[8,9]$, is evaluated by an ergocycle test called YMCA. Very small average estimates of VO2max were observed with girls B1(12.15 $\left.\pm 6.88 \mathrm{~mL} \cdot \mathrm{min}^{-1} \cdot \mathrm{kg}-1\right)$, followed by those of the youngest boysB1 $\left(16.84 \pm 2.77 \mathrm{~mL} \cdot \mathrm{min}^{-1} \cdot \mathrm{kg}^{-1}\right.$ ) (Table 3). Despite the two peaks noted at 41.67 and $43.19 \mathrm{~mL} \cdot \mathrm{min}^{-1} \cdot \mathrm{kg}^{-1}$, in T1 with boys aged between 21 and 24 (Figure 2), the average estimates of $\mathrm{VO}_{2}$ max remained very low for all our study population (Table 3). For [10], they are classified in the category of subjects with low maximal oxygen consumption ( $\left.\mathrm{VO}_{2} \mathrm{max}\right)$. The commonly cited case in the literature for this decrease in $\mathrm{VO}_{2}$ max with girls is the greater accumulation of cutaneous fat during and after puberty [11-14]. These different under-performances, noted with our whole study population, could on one hand be explained by the delay in psychomotor development $[15,16]$ of the visually impaired subjects and, on the other hand, by their lack of initiative and commitment to physical activity [17]. This confirms the hypothesis that the YMCA test on ergometric bicycles undergo by visually impaired people rapidly reveal the cardiorespiratory deconditioning with the latter.

\section{Effectiveness of The Cycloergometer on the Cardiorespiratory Capacity of The Visually Impaired Subject}

At the end of the first evaluation, the intervention plan was designed to improve the aerobic capacity of visually impaired subjects by increasing their maximum oxygen consumption $\left(\mathrm{VO}_{2} \max \right)$ and reducing their heart rate by exertion.

\section{Physical Results}

Eighty-five percent (85\%) of the study participants were successful at the end of the YMCA training sessions, completing at least three consecutive three-minute ergocyle sessions versus $30 \%$ who had passed the first test. This already suggests an improvement in the aerobic capacity of all the participants at the end of the training program. On the physical level, a very significant improvement in the ability of all VIs (84.91\%) to sustain an effort of a progressively high intensity was noted (Figure 2). This improvement is noticed both with the blind and the visually impaired. The success rate increased from $18.42 \%$ to $81.58 \%$ for the blind and from $60 \%$ to $93.33 \%$ for the visually impaired. Furthermore, the two groups, according to the degree of the impairment, differed significantly from each other during the first test $(p=0.003)$, whereas at the last test no significant difference was found at the $5 \%$ threshold as far as the physical resistance between blind and visually impaired is concerned (Table 2). These results show, on the one hand, the vulnerability of the blind, given the weakness of their initial state of health and, on the other hand, the importance of the physical activities adapted to them.

\section{At the Cardiorespiratory Level}

This massive success of all the visually impaired subjects during the third YMCA test resulted in a significant reduction in the $5 \%$ threshold of the average heart rate of all the participants at the end of the study. It increased from $162.84 \mathrm{bpm}$ to $149.78 \mathrm{bpm}$ for boys and from $164.57 \mathrm{bpm}$ to $154.73 \mathrm{bpm}$ for girls for improved but insignificant workloads by gender in the third test (Figure 1). On the other hand, it resulted in a very significant $5 \%$ increase of the average estimates of $\mathrm{VO}_{2} \max$ (Table 3). These variations are only the effect of the adapted training. concluded that the YMCA method seems to be effective in predicting energy consumption at submaximal intensities but not at maximum effort. No significant differences were found between boys B1 and B2 in the 20-24 age group concerning the $\mathrm{VO}_{2} \max$ improvements obtained by them. The first amazed their average V02max estimates from $28.54 \mathrm{~mL} /$ $\mathrm{kg} / \mathrm{min} \pm 10.08$ to $48.50 \mathrm{~mL} / \mathrm{kg} / \mathrm{min} \pm 8.01(70 \%)$. The second ones, from $22.79 \mathrm{~mL} / \mathrm{kg} / \mathrm{min} \pm 12.78$ to $44.94 \mathrm{~mL} / \mathrm{kg} / \mathrm{min} \pm 14.04$ (97\%) (Table 3). Indeed, the effectiveness of an aerobic training (measured by the evolution of $\mathrm{VO}_{2} \max$ ) was shown by Kamelska et al. This latter reported similar results of maximal oxygen consumption with VI subjects using tandem bicycles.

The increases observed in our study ranged from $25 \mathrm{~mL} / \mathrm{kg} /$ min (for boys B1 aged from 15 to 19 and girls B1) to close to $30 \mathrm{~mL} /$ $\mathrm{kg} / \mathrm{min}$ (for boys B1 aged from 25 to 39 and girls B2 aged from 20 to 24). These results are significantly better than those obtained by Tordi et al. [18,19] Taylor et al. who showed a significant increase in maximum oxygen consumption of $18.5 \mathrm{~mL}$. Kg-1 $\mathrm{min}^{-1}$. But they are consistent with those obtained by Grigaliuniené et al. who's average $\mathrm{VO}_{2}$ max of the sample studied was $49.0 \mathrm{ml} / \mathrm{kg} / \mathrm{min}$, considered above the average based on gender and age. This confirms the hypothesis that loss of visual function does not impede the improvement of cardiorespiratory capacity. The average score achieved by girls B1 $\left(38.38 \pm 10.86 \mathrm{~mL} \cdot \mathrm{kg}^{-1} \cdot \mathrm{min}^{-1}\right)$ is still lower than that of boys. The common cause of this $\mathrm{VO}_{2} \max$ reduction (mentioned in books) with girls is the greater accumulation of cutaneous fat during and after puberty. These different increases in $\mathrm{VO}_{2}$ max observed with our study population can be explained by the frequency (three on average per week) and the intensity (85\% of the HR max) of the training program. $[20,21]$ report that these increases in $\mathrm{VO}_{2}$ max are explained by an enzymatic equipment better adapted to oxidative glycogen combustion (or aerobic glycolysis), a better transport and use of oxygen in large quantity. showed that respiratory work of exhalation and deep inspiration develops vital capacity. According to American College of Sports Medicine (1990), data from training studies using subjects with varying levels of $\mathrm{VO}_{2}$ max, body weight and body fat indicate that changes occur in relation to their initial values. This means that the lower the initial level of the $\mathrm{VO}_{2} \max$, the greater the percentage of improvement found. This was verified in the three age groups of the VIs (Table 3) with an invalidation of the idea that there is a correlation between the degree of impairment and the lower level of cardiorespiratory condition.

\section{At the Psychosocial Level}

The enthusiasm, joy and enjoyment observed during and after the workouts demonstrate that the study enabled participants to:

a) Benefit from resource-supported attention (eg skills, abilities, social support from all CNHU-HKM users), thus allowing them to control their own live;

b) Take responsibility for changes leading to healthy and active life and positive mental health [22,24].

With regard to the new aerobic capacity acquired by the VI subjects after the training sessions, there was a significant improvement in the health benefits of the participants: $20.83 \%$ of 
a good "health benefit" $\left(30<\mathrm{VO}_{2} \mathrm{max} \leq 40 \mathrm{~mL} \cdot \mathrm{kg}^{-1} \cdot \mathrm{mn}^{-1}\right) ; 37.5 \%$ of a very good "health benefit" $\left(40<\mathrm{VO}_{2} \max \leq 50 \mathrm{~mL} \cdot \mathrm{kg}^{-1} \cdot \mathrm{mn}^{-1}\right)$ and $35.42 \%$ of excellent "health benefit" (Meen, 2000). In contrast, only $6.25 \%$ of visually impaired subjects did not benefit from the training program (Figure 3). This may be related to an increased psychomotor retardation noticed with visually impaired subjects [25-27].

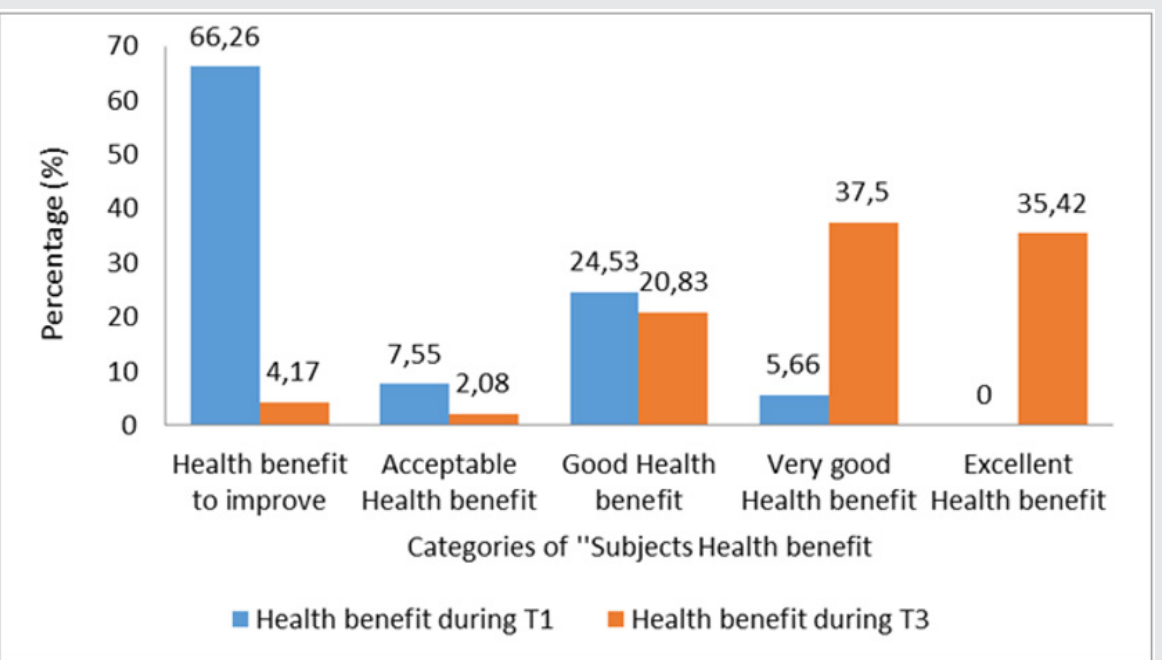

Figure 3: Evolution of the participant health benefits at the beginning and at the end of the study. Figure 3 shows the beneficial effects of the training program on the health of almost all subjects at a significant $5 \%$ threshold.

\section{Conclusion}

The first observation of this study is that the overall results show, on the one hand, the vulnerability of the blind, given the weakness of their initial state of health, on the other hand, the importance of the activities that are adapted to them. With the use of the ergocycle, the visually impaired subject can independently and significantly improve some basic fitness parameters such as cardiorespiratory capacity [28-30]. This study, by offering all the visually impaired subjects' access to health services through the practice of cycloergometer physical activities, made it possible to highlight the aerobic endurance training of the visually impaired subjects whatever the age, gender and the degree of vision loss.

\section{Limitations of The Study}

The enthusiasm aroused by the use of the ergocycle that is unknown by $72 \%$ of the participants and the commitment of the subjects who found $98 \%$ in this study an opportunity to improve their health and overcome sedentary lifestyle did not make it possible to set up a control group able to highlight another form of exclusion. Furthermore, the study did not distinguish thenative B1s (blindness occurring to less than 3 years old) from the late B1s or B2s (severeimpairment) from B3s (medium impairment), which may have different reactions to the training.

\section{Acknowledgment}

The completion of this study would not have been possible without the availability and support of several people including David and all his visually impaired friends who were willing to participate in the study, as well Mrs. GOUHOUE Marie, a teacher at CPSAA. My thanks also go to my supervisors, Professors Mansourou Mohamed LAWANI and Toussaint KPADONOU for agreeing to lead this work by giving me their full availability. Finally, my thanks to all those who have contributed to this work.

\section{References}

1. Kora Zaki Yarou S, Lawani MM, Kpadonou T (2012) Intégration des déficients visuels à la pratique de l'Education Physique et Sportive (EPS). dans les écoles et collèges d'enseignement du Bénin J Rech Sci Univ Lomé 14(2): 211-219.

2. Asher R (1974) The danger of going to bed. Brit Med J pp. 967-968.

3. Alikhan R, Cohen AT, Combre S, Samama M, Desjardins L, et al. (2004) Risk factors for venous thromboembolism in hospitalized patients with acute medical illness. Arch Intern Med 164(9): 963-968.

4. Golding L (2000) The "Y's" way to Physical Fitness. Human Kinetics Champaign IL 2000.

5. Kamelska AM, Mazurek K, Zmijewski P (2015) Visual impairment does not limit training effects in development of aerobic and anaerobic capacity in tandem cyclists. J Hum Kinet 48: 87-97.

6. Stainback S, Stainback W, East K, Sapon-Shevin M (1994) A commentary on inclusion and the development of a positive self-identity by people with disabilities. Exceptional Children (54): 486-490.

7. Lieberman L, McHugh E (2010) Health-Related Fitness of Youths with Visual Impairments. J Vis Impair Blind (104): 349-359.

8. McGill SM, Childs A, Liebenson C (1999) Endurance times for low back stabilization exercises: clinical targets for testing and training from a normal database. Arch PhysMed Rehabil 80(8): 941-944.

9. Sparling PB, Millard Stafford M, Snow TK (1997) Development of a cadence curl-up test for college students. Res QExerc Sport 68(4): 309316.

10. Meen HD (2000) Physical activity in children and adolescents in relation to growth and development. Tidsskr Nor Laegeforen 120(24): 29082914

11. Redondo B (2000) Isostreching, la gymnastique du dos. 4ème édition. Paris Chiron 2000.

12. Astrand PO, Rodahl K (1987) Textbook of work physiology. Med Sci Sports Exerc (19):310-317.

13. Bosquet L, Leger L, Legros P (2000) Les méthodes de détermination de l'endurance aérobie. Sci sports 15(2): 55-73. 
14. Weissland $T$ (2001) Reconditionnement musculaire et lombalgie chronique. Kiné Sci (417): 6-12.

15. De Potter JC (2006) Contribution de l'activité physique et sportive au bien être des personnes déficientes visuelles. Sciences et Sports 21(4): 249-250.

16. Gawlik K (2008) The influence of visual impairment on selected aspects of somatic and motor development of children and adolescents. Katowice: AWF

17. Zolla E (2005) Déficience visuelle et adolescence. In: Réadaptation (517): $22-24$

18. Tordi N, Gimenez M, Predine E, Rouillon JD (1998) Effects of an interval training programme of the upper limbs on a wheelchair ergometer in able-bodied subjects. Int J Sports Med 19(6): 408-414.

19. Taylor AW, McDonell E, Brassard L (1986) The effects of an arm ergometer training programme on wheelchair subjects. Paraplegia 24(2): 105-114.

20. Cazorla G (1990) Tests de terrain pour évaluer la capacité aérobie et la vitesse aérobie maximale. Actes du colloque international de la Guadeloupe. Eds: ACTSCHING \& AREAPS 151-173.

21. Bar-Or 0 (1983) Pediatric sports medicine for the practitioner. New York Springer-Verlag pp. 376

22. Hutzler Y, Sherrill C (1999) Disability, physical activity, psychological well-being and empowerment: A life span perspective. In: Lidor R Bar-Eli M editors Sport psychology : Linking theory and practice. Morgantown (WV) Fitness Information Technology 281-300.

\section{ISSN: 2574-1241}

DOI: 10.26717/BJSTR.2019.19.003262

Salifou Kora Zaki Yarou. Biomed J Sci \& Tech Res

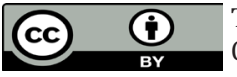

This work is licensed under Creative Commons Attribution 4.0 License

Submission Link: https://biomedres.us/submit-manuscript.php
23.Zimmerman M, Rappaport J (1988) Citizen participation, perceived control, and psychological empowerment. American Journal of Community Psychology 16(5): 725-750.

24.(1990) American College of Sports Medicine. The recommended quantity and quality of exercise for developing and maintaining the cardiorespiratory and muscular fitness in healthy adults. Med Sci Sports Exerc (22): 265-274.

25. Armstrong N, Welsman JR (1996) Assessment and Interpretation of aerobic fitness in children and adolescents. Int. J. Sports Med 17: 356359.

26. Armstrong N, McManus AM, Welsman JR (1994) Children's aerobic fitness. Br J Phys Educ 25: 9-11.

27. Grigaliūnienė A, Ramonas A, Celutkienè J, Sileikienè V, Rudys A, et al. (2013) Cardiorespiratory parameters of exercise capacity in a healthy Lithuanian population: the pilot study. Hellenic J Cardiol 54(2): 107-118.

28. (2010) Guide du Conseiller en Condition Physique et Habitudes de Vie. Société Canadienne de Physiologie de l'Exercice (SCPE). 3ème édition supplement 2010.

29. Gutierrez L (1994) Beyond Coping: An empowerment perspective on stressful life events. Journal of Sociology and Social Welfare 21(3): 201220.

30. Rowland TW (1990) Development aspects of physiological function relating to aerobic exercise in children. Sports Medicine 10(4): 255-266.

$\begin{array}{ll}\text { BIOMEDICAL } & \text { Assets of Publishing with us } \\ \text { RESEARCHES } & \text { - Global archiving of articles } \\ \text { - Immediate, unrestricted online access }\end{array}$

